IP Periodica Polytechnica
Transportation Engineering

42(1), pp. 43-48, 2014

DOI: $10.3311 /$ PPtr.7261

http://www.pp.bme.hu/tr/article/view/7261

Creative Commons Attribution (i)

RESEARCH ARTICLE

\section{Analysis of influence of bearing clearance on the static carrying capacity of multi-row slewing bearings}

Marek Krynke / Stanisław Borkowski / Jacek Selejdak

RECEIVEd 14 November 2013; Accepted 10 January 2014

\section{Abstract}

The effect of selected bearing clearances in double row ball bearing and three row roller on their static carrying capacity is presented in the paper. An original method of determination of these profiles by means of the author's program that was based on a calculation model with rigid rings was proposed. This program allows on automated preparation of static load carrying capacity profile for the different defined values of clearance bearing. This consideration is illustrated by an example that was carried out for bearing in nominal state i.e. bearings without clearance and for acceptable value of bearings clearances that was defined by producer. Some specific points of bearing's operation and the distribution of internal load for these areas were also discussed. A mechanism of formation this load distribution on individual rolling elements of bearing was discussed. The detailed description of the course of the carrying capacity characteristics with repeated appearing of the local minimum was made.

\section{Keywords}

Bearing clearance $\cdot$ Slewing bearing $\cdot$ Load bearing capacity

\section{- Load distribution}

\section{Marek Krynke}

Institute of Production Engineering, Faculty of Management,

42-200 Czestochowa, ul. Armii Krajowej 19b, Poland

e-mail: krynke@zim.pcz.pl

Stanisław Borkowski

Institute of Production Engineering, Faculty of Management,

42-200 Czestochowa, ul. Armii Krajowej 19b, Poland

e-mail: bork@zim.pcz.pl

Jacek Selejdak

Department of Building Construction and Engineering,

Faculty of Civil Engineering, 42-200 Czestochowa, ul. Akademicka 3, Poland e-mail: jaceksel@poczta.onet.pl

\section{Introduction}

Rolling slewing bearings are currently the most popular connections between chassis and body in heavy-duty machines (Fig. 1). Due to their compact design, these bearings represent an optimum solution in the rotation nodes in such machines as building cranes, dock cranes, ship board cranes, excavators, loaders, stackers, wheeled cranes, wind power plants, oil platforms, antennas and radars etc.

The most essential utility-based characteristic that distinguishes slewing bearings from conventional bearings is their ability to carry, besides axial $(Q)$ and radial $(H)$ load, torques $M$ which are applied in the planes that go through bearing axis (Fig. 2).

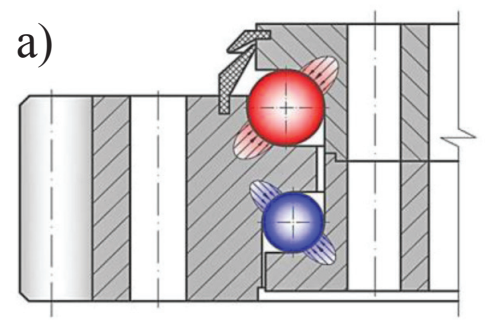

b)

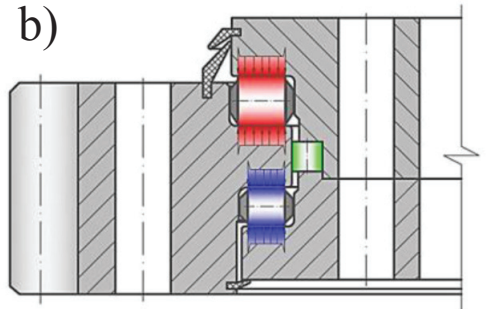

Fig. 1. Slewing bearings: double-row ball bearing (a) and three-row roller bearing (b)

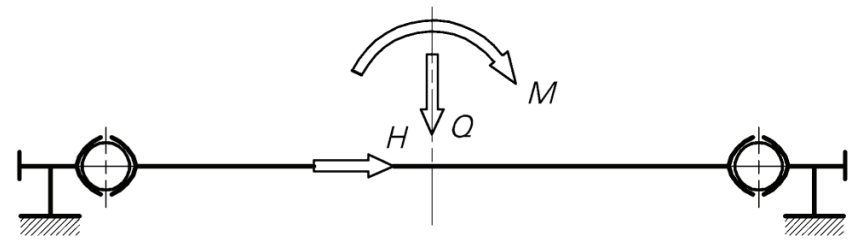

Fig. 2. Components of external load of slewing bearing 
The load that is transferred from the body to the chassis of a machine causes that high forces are generated in the area of contact between rolling elements and races. These forces might lead to changes in dimensions and deformation of bearings' rings. This causes that load distribution on the race's circumference is uneven. Load distribution depends on the type of bearing, its dimensions, ring rigidity and rigidity of the supporting structures (Kania L., 2005, Smolnicki T., 2002, Borkowski S., Krynke M., Selejdak J. 2011).

Slewing bearings operate at very low rotational speed of several rotations per minute. In certain machines, the peak load to the bearing does not occur during rotational motion but at rest. For this reason, the main parameter determined for these bearings is static load capacity, which is largely determined by the maximum permissible pressure in the contact zone of the most loaded rolling element.

Slewing bearings are selected on the basis of the characteristics of capacity, which determine the area of the permissible load of the bearing. This capacity of a bearing, called the catalogue capacity, does not take into account the real conditions of bearing work as the conditions of the future application of the bearing are unknown. Because at design and production stage, the real conditions of bearing work cannot be determined, the catalogue capacity is computed using analytical methods on the basis of simplified assumptions defined by Ohnrich (Ohnrich S. 1959) and Matthias (Matthias K. 1963) with later supplements given in works (Gibczyńska T., Pytko S. 1999, Amasorrain J.I., Sagartzazu X., Damián J. 2003, Kania L. 2005) and many more. Non-deformability of bearing rings is often the most important assumption. This involves the next assumption that bearing clamping bolts do not have an influence on bearing capacity. Thus, the capacity of the bolt connection of bearing rings with the bearing mounting is computed independently on computations of bearing capacity. The capacity of the bolt connection can only limit the area of the permissible load of the slewing bearing. In the real conditions of bearing work, bearings and clamping bolts undergo deformations and bearing capacity differs from the capacity determined under the above assumptions. Many factors have an influence on the bearing capacity, including the deformation state of the support structures of the bearing analysed for example by Smolnicki (Smolnicki T. 2002, Smolnicki T., Derlukiewicz D., Stańco M. 2008), Zupan and Prebil (Zupan S., Prebil I. 2001), Daide and others (Daidie A., Chaib Z., Ghosn A. 2008). At an initial design stage, the machine designer does not have access to this information, so the bearing catalogue is the only source of information about the bearing. Also, the machine designer does not have information about its future application.

Clearance in a slewing bearing is an important parameter An initial value of clearance is slight and during work it is increasing due to wearing of the bearing raceway. Producers usually name the boundary values of clearance permissible in a bearing. Computations, carried out using model with the rigid rings, point high decrease in capacity already for small values of clearance. Clearance reduces bearing capacity because clearance causes diminution of the region of active circuit of a bearing in support row.

In the three-row roller bearings effect of clearance is higher than in single-row roller bearings, but the character of phenomenon is similar. Naturally, clearance cannot have too high values because of correct work of bearing. Then the load conditions of individual rollers are changing in roller bearings. Nonuniform distribution of the load along generating line of the roller causes decrease in the value of the limiting load of the roller. In the ball bearings, clearance has an influence on the change in action angle of a bearing.

Different constructional features of slewing ball and roller bearings affect static load capacity profiles for these bearings. The load which occurs in ball bearings causes that the directions (angle of operation) of forces transferred through rolling elements change, whereas roller bearing are characterized by higher rigidity of the system of rolling element-race, which translates into higher susceptibility to axial play (Krynke M., Selejdak J., Borkowski S. 2012a, b, Ulewicz R. 2003).

The present paper illustrates and compares catalogue-based static load capacity profiles for the two types of slewing bearings: double-row ball bearings (Fig. 1a) and three-row roller bearings (Fig. 1b). The characteristic areas of bearing's operation for different loads of the bearing with axial force and the torque $\mathrm{M}$ were discussed. These profiles took into consideration the effect of axial play. The distributions of internal load in bearings in the nominal state were compared with the distributions for permissible axial play with respect to specific points of operation.

\section{Calculation Methodology}

Choosing slewing bearings from a catalogue or designing a bearing for a particular machine is carried out based on static load capacity profiles. The most popular load capacity profile is the diagram of $M=f(Q)$. These diagrams illustrate a nominal load capacity without taking into consideration the effect of play and are presented in catalogues of slewing bearings (Rothe Erde 2008).

Classical calculation models used for determination of static load capacity profile are often construed based on the simplification assumptions which are adopted for stationary machines where bearings are closely related to the load-carrying structures with high rigidity.

The calculations used computer software for determination of load capacity in slewing bearings based on the methods presented in the studies (Mazanek E., Krynke M. 2012, Krynke M., Kania L., Mazanek E. 2012). The calculation model in this software adopts a classic set of simplification assumptions (Mazanek E., Krynke M. 2011) e.g. non-deformability of bearing rings which are moving with respect to each other as solids. 
Another assumptions included:

- ideal shapes of rings and rolling elements,

- the same diameter of all rolling parts selected from one manufacturing batch using the dimension-based selection criteria and adopting the deviations of roller or ball diameter of $\pm 1 \mu \mathrm{m}$.,

- the same hardness of all bearing's races: races in a bearing are induction-hardened and ground and the roughness class amounts to $\mathrm{Ra}=0,63 \mu \mathrm{m}$. Other requirements connected with assembly of these bearings were discussed in the study (Borkowski S., Krynke M., Selejdak J. 2011),

- maximum load of a rolling element is represented by the force which causes a plastic strain of $\delta \mathrm{pl} \mathrm{dop} / \mathrm{d}=0,0002$ (Kania L. 2006).

\section{Results of calculation of load capacity and analysis}

Calculations of the load capacity profiles of slewing bearings were made for a double-row ball bearing and three-row roller bearing with the parameters as presented in Table 1 .

Figure 3 presents the charts that illustrate static load capacity profiles for the slewing bearings: a double-row slewing bearing (Fig. 3a) and three-row roller bearing (Fig. 3b) The charts also show the scopes of specific cases of operation of bearings for nominal states (without play) and the cases of presence of permissible axial play. In the AE range, the load capacity is determined by the load capacity of a row which is limited by the permissible force $F_{1 \text { dop }}$ of a rolling element which is present in the bearing node. Bearing node it is the sector of the bearing in the plane where the torque $M$ is applied.

The $\mathrm{AB}$ range is the place where only rolling elements of the load-carrying row are operating while rolling parts in the supporting row do not take part in transferring the external load. The rolling elements which are present in the nodes A and B (point E) have limited load values of $F_{1 d o p}$ and $F_{2 d o p}$. The load capacity in the EF range is determined by the strength of the supporting row.

The supporting row in the ball bearings studied starts to operate at relatively high torques. Greater operating area where bearing rings are not detached from the structures is observed in the three-row roller bearings. This results from the bearing design. The operating angle of rolling elements in the loadcarrying and supporting rows of the three-row roller bearing amounts to $90^{\circ}$, which causes that the radial displacement of the bearing ring does not affect the range of load with the torque $M$ and the axial force $Q$. In order to transfer the radial load $H$, an additional row of side rollers with axes parallel to the bearing's axis was designed in the three-row roller bearing. When the bearing is not loaded with the radial force, an axial displacement of rings is observed in three-row roller bearings, whereas radial displacements depend on the magnitude of radial play and rigidity of the system of rolling element with race in the side roller row (Kania L., Krynke M., Mazanek E. 2012).
Tab. 1. Parameters of slewing bearings analysed in the study

\begin{tabular}{cccc}
\hline Bearing type & & $\begin{array}{c}\text { Double-row } \\
\text { ball bearing }\end{array}$ & $\begin{array}{c}\text { Three-row } \\
\text { roller bearing }\end{array}$ \\
\hline $\begin{array}{c}\text { Rolling diameter } \\
\text { of a calculation row [mm] }\end{array}$ & $d_{t 1}$ & 1400 & 1400 \\
$d_{t 2}$ & 1396 & 1396 \\
\hline $\begin{array}{c}\text { Diameter of rolling } \\
\text { elements [mm] }\end{array}$ & $d_{1}$ & 30 & 25 \\
\hline $\begin{array}{c}\text { Number of rolling elements } \\
\text { in the calculation row, }\end{array}$ & $z_{1}$ & 25 & 30 \\
\hline Roller length [mm] & $z_{2}$ & 150 & 126 \\
\hline Contact coefficient & $l_{1}$ & - & 151 \\
\hline Operation angle [deg] & $k_{p}$ & 0.96 & 28 \\
\hline Race hardness & & $45^{\circ}$ & - \\
\hline
\end{tabular}

a)

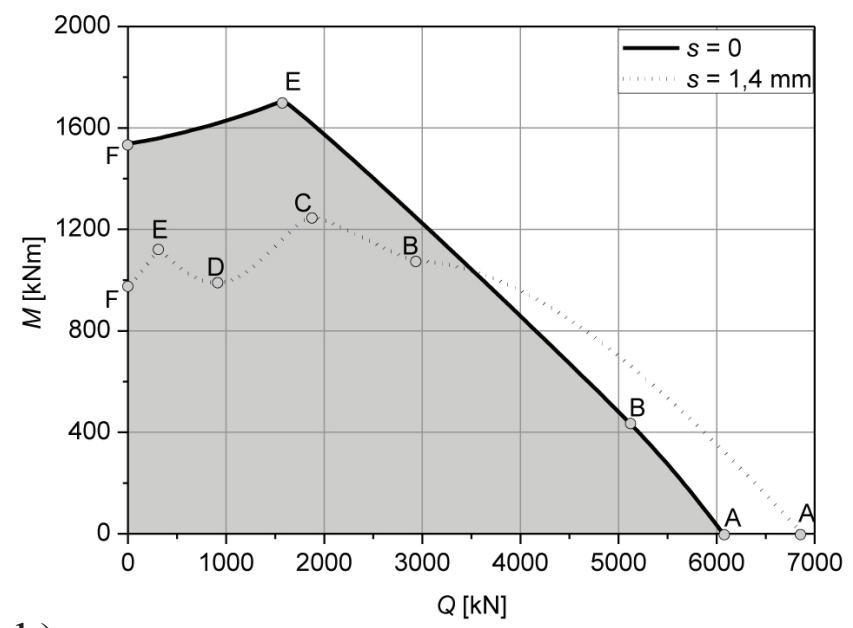

b)

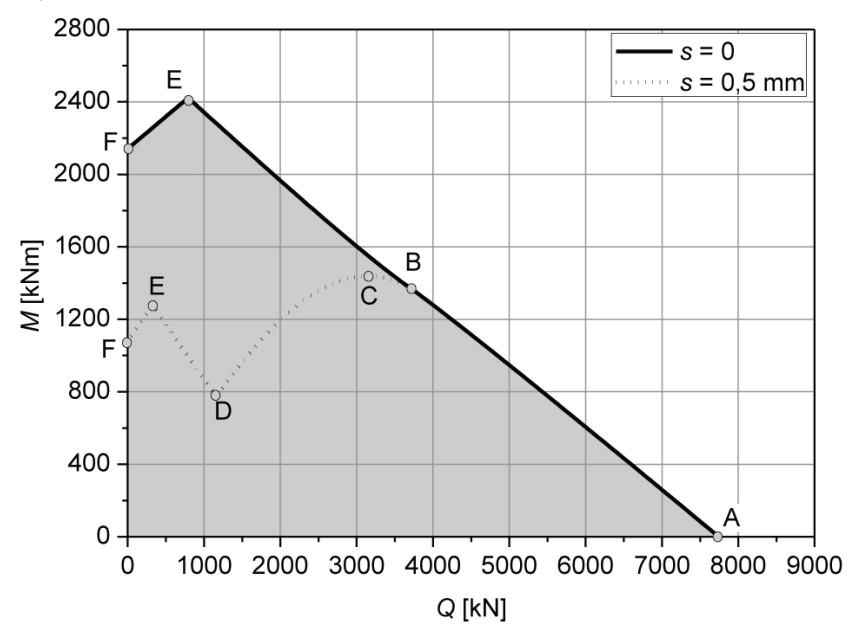

Fig. 3. Static load capacity for a double-row bearing (a) and three-row roller bearing (b) in a nominal state (continuous line) and a bearing with axial play of $\mathrm{s}=1.4 \mathrm{~mm}$ and $\mathrm{s}=0.5 \mathrm{~mm}$ (dotted line), respectively 


\section{Distribution of internal load \\ Double row ball bearing}

Figure 3a illustrates load capacity profiles for a double-row ball bearing in nominal state (without play) and for a -bearing with axial play that amounts to $1.4 \mathrm{~mm}$. The profile that characterizes the load capacity with play contain the points A, B, C, D, E, F which denote specific areas of operation of a slewing bearing. For these specific operation points, Fig. 4 presents distribution of internal load in the bearing. In the point A, where the bearing transfers only axial forces, the load capacity increases compared to the non-play bearing. This results from higher operating angle of rolling elements in the bearing with play. The $\mathrm{AB}$ range is the place where all rolling elements of the load-carrying row are operating while rolling parts in the supporting row do not take part in transferring the external load. From the point $\mathrm{B}$ on, the rolling elements in the supporting row start operating; thus insignificant decline in the profile in this point (Fig. 3a). An additional increase in load capacity occurs in the $\mathrm{BC}$ range due to even greater use of rolling parts in the supporting row with high contribution of the rolling parts of the supporting row. Another decline in the profile is observed in the point C (Fig. 3a). The load capacity reduces until it reaches the point $\mathrm{D}$ with the lowest value of load capacity. In the load area of the section $\mathrm{CD}$, the play between the rolling elements and races causes that the active sections of the bearing's race are reducing with relatively insignificant use of rolling elements in the supporting row; hence a decline in load capacity in this range of load. An increase in load capacity is observed in DE range, which is caused by higher contribution of load capacity of the supporting row until it reaches the value in the point E, where rolling parts present in the bearing node reach the permissible load $\left(F_{\text {Idop }}\right.$ and $\left.F_{2 d o p}\right)$. The load capacity in the EF range is determined by the strength of the supporting row.

\section{Three row roller slewing bearing}

Figure 5 presents distributions of internal load in a three-row roller bearing in the characteristic points marked with letters A, $\mathrm{B}, \mathrm{C}, \mathrm{D}, \mathrm{E}$ and $\mathrm{F}$ points in Fig. 3b. In the range of the bearing load in the section $\mathrm{AB}$, all the rolling elements in the supporting row take part in the transfer of the external load. In supporting row, the same as in the double row ball bearing, rolling parts are not loading. In the BD range, as a result of the axial play, a part of rolling elements stops operating, while the fewest number of the operating elements is observed in the point $\mathrm{D}$. This leads to the decline in load capacity in this range. Furthermore, an increase in the load capacity is observed in the section DE of the profile. This is caused by the operation of roller elements in the supporting row, where the limiting value is reached in point $\mathrm{E}$ by the rolling parts present in the bearing nodes. The load capacity in the EF range is determined by the strength of the supporting row.

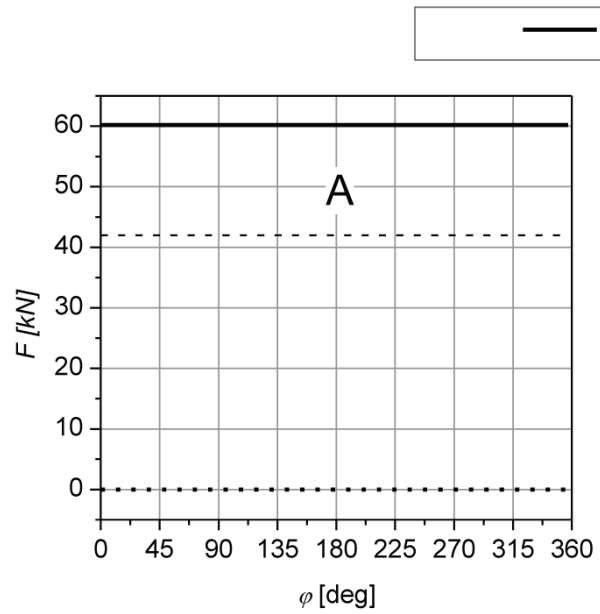

$F_{1} \quad \cdots \cdots F$

$F_{1 \text { dop }} \cdots F_{2 d o p}$ $s=0$
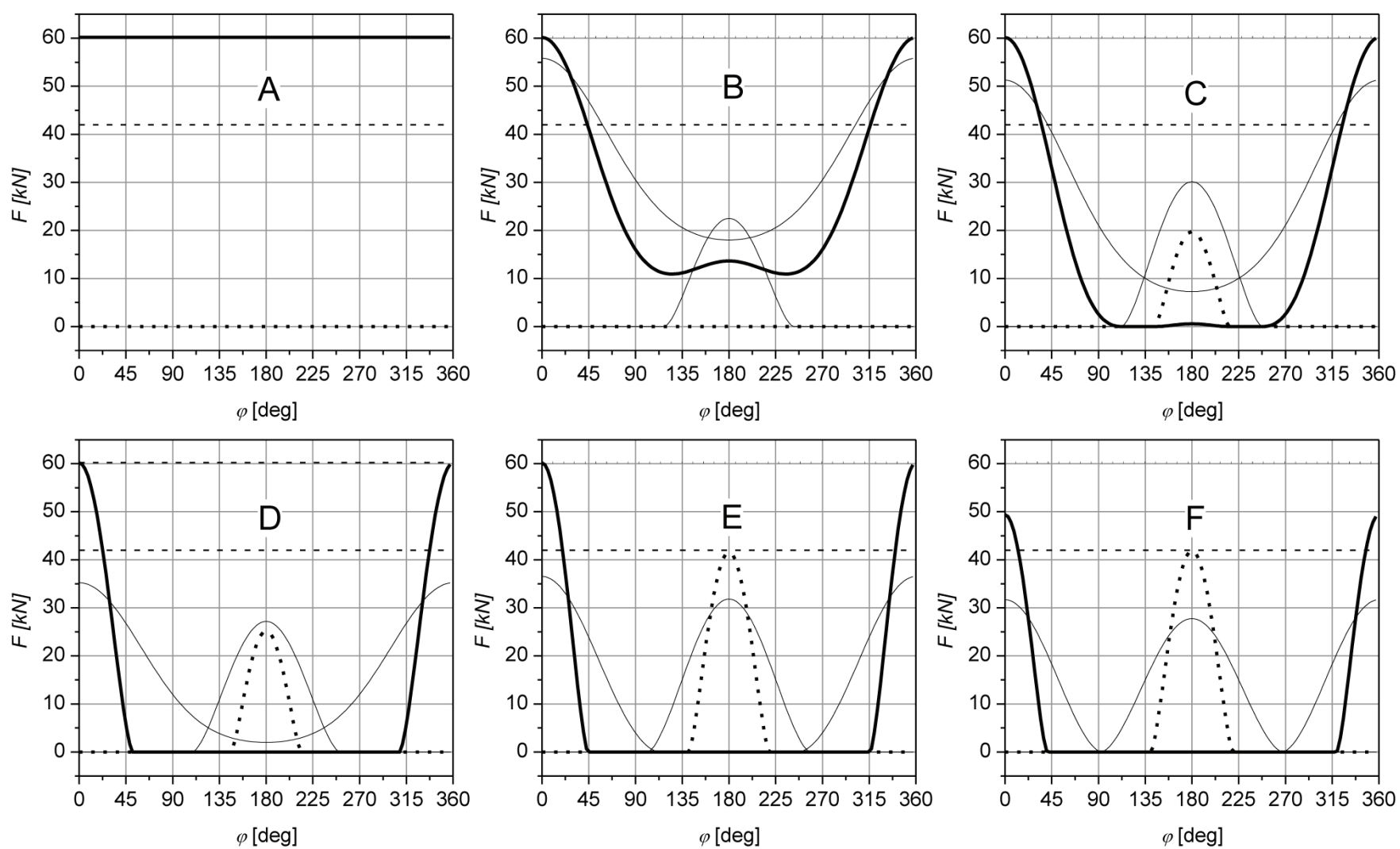

Fig. 4. Distribution of the external load in the double-row ball bearing with axial play of $\mathrm{s}=1.4$ mm for individual points $\mathrm{A}$, B, C, D, E and $\mathrm{F}$ marked in Fig. 3a 


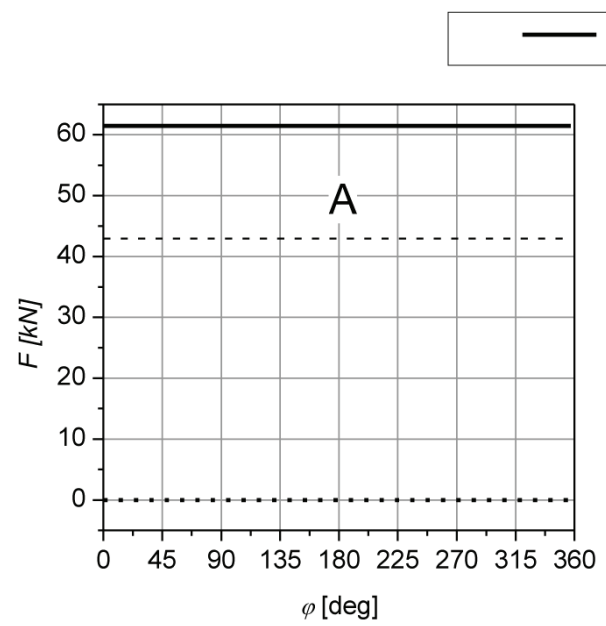

$F_{1} \cdots \cdots F_{2} \cdots F_{1 d o p}-\cdots F_{2 d o p}$

$s=0$
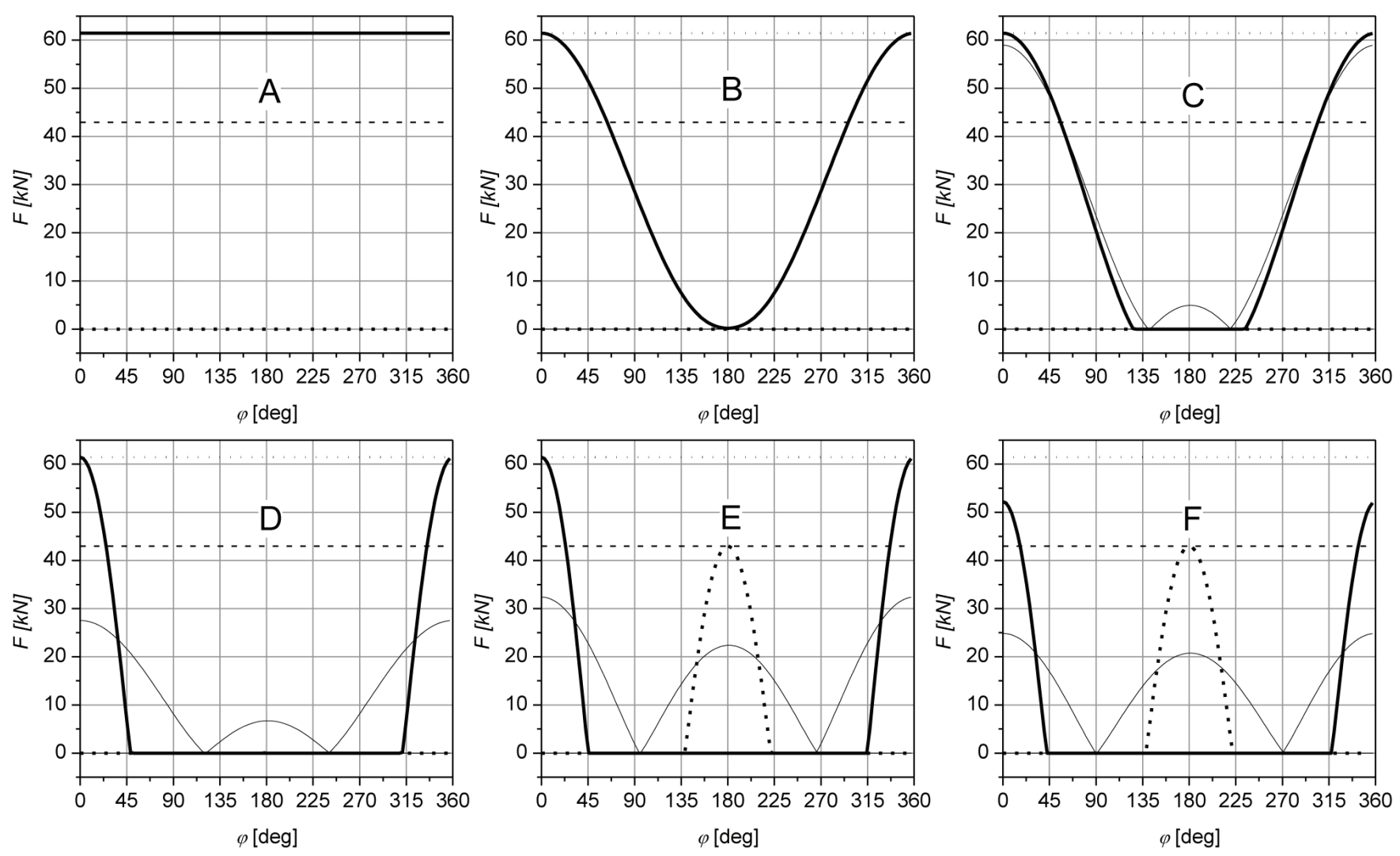

Fig. 5. Distribution of the external load in the three-row bearing with axial play of $\mathrm{s}=0.5 \mathrm{~mm}$ for individual points $\mathrm{A}$, B, C, D and $\mathrm{E}$ marked in Fig. $3 \mathrm{~b}$

\section{Conclusion}

The static load capacity profiles presented in this paper were obtained by means of computer software which uses calculation methods based on the assumption that the bearing rings are nondeformable. Therefore, the profiles relate to the slewing bearings with medium and small diameters of up to $2 \mathrm{~m}$, fixed on a very rigid seat. The highest static load capacity is ensured by stationary equipment with bearing's rings fixed on a pipe with thick flange e.g. dock cranes, wind power plants etc. while in mobile machines, such as excavators, the load-carrying structures fail to show satisfactory rigidity due to the limited dimensions (Kania L., Krynke M. 2013). With these applications, higher safety coefficients should be adopted with respect to the capacity evaluated or it is recommended to use calculation methods which allow for taking into consideration the susceptibility of bearing rings, rigidity of seats in load-carrying and supporting structures and rigidity of screw connection which fixes the slewing bearing.

The examples of the calculations carried out in this study for load capacity (taking into consideration the axial play) allowed for determination of internal load distributions which were used for calculation of static load capacity. The results obtained in the study were compared with the static load capacity profiles obtained for bearings in nominal state (without play). Excess bearing play is very unfavourable for operation of slewing bearings. It causes a reduction in the load capacity of bearings and contributes to the deterioration of the conditions of contact between the pinion and toothed ring due to unequal distribution of load along the tooth line.

Because of high rigidity of the system of rolling elementrace, three row roller bearings exhibit the highest load capacity; therefore they are recommended for the machines that carry the highest load. However, this design of bearings also increases their susceptibility to axial play. The analysis carried out in this study demonstrates that even insignificant play in the case of three-row roller bearings causes a reduction in contribution of active sections of the race to transfer of the external load and thus a reduction in load capacity of the bearing.

\section{References}

1 Amasorrain J. I., Sagartzazu X., Damián J., Load distribution in a four contact-point slewing bearing, Mechanism and Machine Theory, 38 (6), 479-496 (2003). DOI: $\underline{10.1016 / \mathrm{S} 0094-114 \mathrm{X}(03) 00003-\mathrm{X}}$

2 Borkowski S., Krynke M., Selejdak J., Evaluation of Carrying Capacity Three-Row Slewing Roller Bearing, Perner's Contacts, 6 (2), 98-105 (2011). 
3 Daidie A., Chaib Z., Ghosn A., 3D simplified finite elements analysis of load and contact angle in a slewing ball bearing. Journal of Mechanical Design, 130 (8), 082601 (8 p.) (2008).

DOI: $10.1115 / 1.2918915$

4 Gibczyńska T., Pytko S., Rolling slewing bearings, AGH University of Science and Technology Press, Kraków (in Polish) (1999).

5 Kania L., Modelling of rollers in slewing bearing calculations with the use of finite elements, Mechanism and Machine Theory 41 (11), 1359-1376 (2006). DOI: $10.1016 /$ i.mechmachtheory.2005.12.007

6 Kania L., Analysis of internal load of slewing bearings in respect of their load carrying capacity, Wydawnictwo Politechniki Czestochowskiej, Czestochowa (in Polish) (2005).

7 Kania L., Krynke M., Computation of the general carrying capacity of slewing bearings, Engineering Computations, 30 (7), 1011-1028 (2013). DOI: $10.1108 / E C-02-2012-0023$

8 Kania L., Krynke M., Mazanek E., A Catalogue Capacity of Slewing Bearings, Mechanism and Machine Theory, 58, 29-45 (2012). DOI: 10.1016/j.mechmachtheory.2012.07.012

9 Kania L., Śpiewak S., The effect of bearing clearance on the static carrying capacity of twin slewing bearings in reference to friction torque, Pomiary, Automatyka, Kontrola, 58 (1), 119-122 (2012).

10 Krynke M., Kania L., Mazanek E. Modelling the Contact Between the Rolling Elements and the Raceways of Bulky Slewing Bearings, Key Engineering Materials, 490, 166-178 (2012). DOI: 10.4028/www.scientific.net/KEM.490.166

11 Krynke M., Selejdak J., Borkowski S., Determination of static limiting load curves for slewing bearing with application of the finite element method - Technical Paper, Materials Engineering, 20 (2), 64-70 (2013).
12 Krynke M., Selejdak J., Borkowski S., Diagnosis and Damage of Bearings, Manufacturing Technology 12 (13), 140-144 (2012a).

13 Krynke M., Selejdak J., Borkowski S., The Quality of Materials Applied for Slewing Bearing Raceway - Technical Paper, Materials Engineering, 19 (4), 157-163 (2012b).

14 Matthias K., Calculation of the large diameter bearings, Hebezeuge und Fördermittel, 3 (9) 275-290 (in German) (1963).

15 Mazanek E., Krynke M., Comparisons of the load carrying capacity of roller and ball bearings characteristics, Przegląd Mechaniczny 70 (11), 29-33 (in Polish) (2011).

16 Mazanek E., Krynke M., Computer program for calculation of capacity of rolling slewing bearings, Przegląd Mechaniczny 71 (4), 35-38 (in Polish) (2012).

17 Ohnrich S., Calculation of the double-row large diameter bearings, Institut für Fördertechnik, Leipzig (in German) (1959).

18 Rothe Erde - Slewing Bering (2008), Katalog.

19 Smolnicki T., (2002). Physical aspects of coherence of large-size rolling bearings and deformable support structures, Wrocław University of Technology PublishingHouse, Wrocław (in Polish) (2002).

20 Smolnicki T., Derlukiewicz D., Stańco M., Evaluation of load distribution in the superstructure rotation joint of single-bucket caterpillar excavators, Automation in Construction 17 (3), 218-223 (2008). DOI: $10.1016 /$ j.autocon.2007.05.003

21 Ulewicz R., (2003). Quality Control System in Production of the Castings from Spheroid Cast Iron, Metalurgija 42 (1), 61-63 (2003).

22 Zupan S., Prebil I., Carrying angle and carrying capacity of a large single row ball bearing as a function of geometry parameters of the rolling contact and the supporting structure stiffness, Mechanism and Machine Theory, 36 (10), 1087-1103 (2001).

DOI: $\underline{10.1016 / \mathrm{S} 0094-114 \mathrm{X}(01) 00044-1}$ 